\title{
Practice Affairs Committee
}

\section{Committee Chair: Dan Sadowski MD FRCPC - Edmonton}

Members: Marty Fishman MD FRCPC, Andre Gelly MD FRCPC (ad hoc member), Roger Hollingworth MD FRCPC, John Marshall MD FRCPC, John Morse MD FRCPC, Anthony Nestel MB FRCPC, Imran Rasul MD FRCPC, Eric Walli MD FRCPC

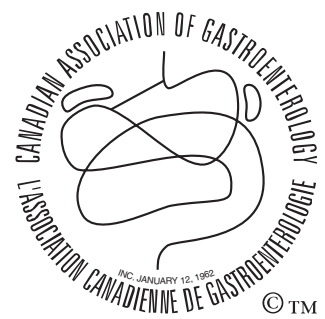

En français voir page 417
$T^{\text {he }}$ he Practice Affairs Committee has had a productive year representing the interests of gastroenterologists involved in clinical care. The principle mandate of the committee is to address all issues relevant to the practice of gastroenterology, such as participation in the development of clinical practice guidelines and education programs, and the facilitation of clinical research. A major activity in 2003 was participation in the drafting of several new clinical practice guidelines:

- Infliximab and the management of Crohn's disease;

- Screening for colorectal cancer; and

- Management of gastroesophageal reflux disease.

Another key responsibility of the committee is administration of the Clinician's Professional Enrichment Grant (CPEG). In the fall of 2003, the governing board increased the maximum amount available to $\$ 20,000$. Funds can be used to offset travel, living and overhead expenses. The CPEG provides physicians in clinical practice with the opportunity to obtain additional clinical training, which can further enhance their professional lives and provide added value to the communities they serve. Previous recipients of the awards have used the funds to develop expertise in advanced endoscopic techniques, endoscopic ultrasound and clinical nutrition. Some of the many other eligible opportunities include training in capsule endoscopy, motility testing, inflammatory bowel disease clinical care, hepatology, clinical trials and nutrition. The

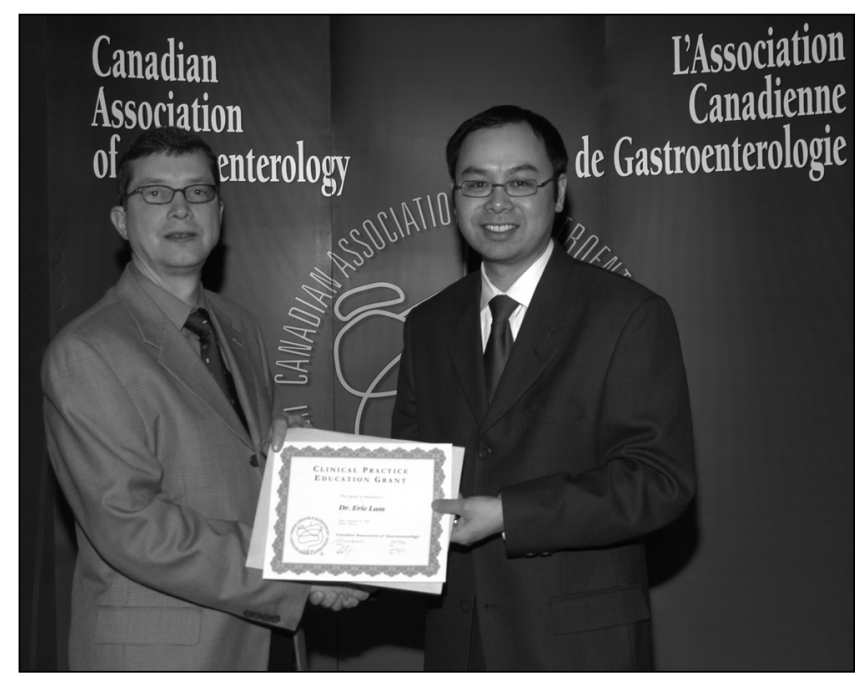

Dr Dan Sadowski, Chair of the Practice Affairs Committee, presents the 2003 Clinical Practice Education Grant to Dr Eric Lam. Dr Lam will be using the funds to develop skills in endoscopic ultrasound

terms of reference for the grant and an application form may be found on the CAG Web site at <http://www.cag-cg.org/spon sors/clinical_traineeship.htm>
Abbott Laboratories Ltd.
AstraZeneca Canada Inc.
Axcan Pharma Inc.
Janssen-Ortho Inc.
Pfizer Canada Inc. 


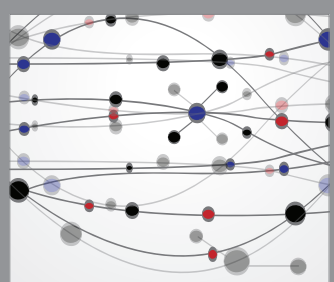

The Scientific World Journal
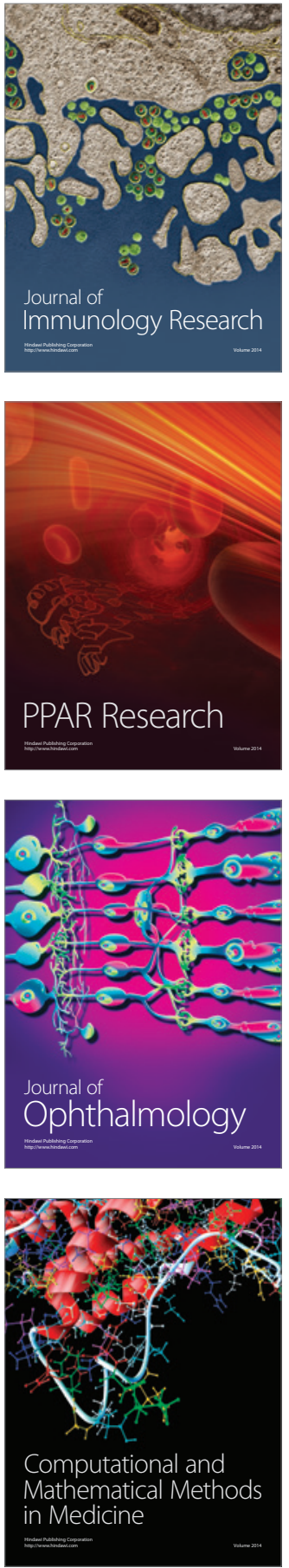

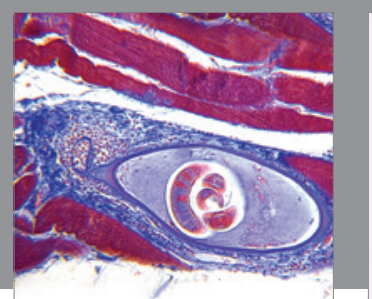

Gastroenterology Research and Practice

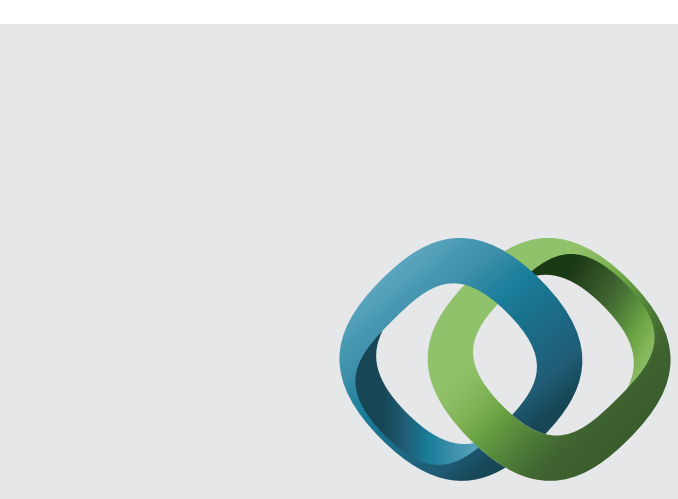

\section{Hindawi}

Submit your manuscripts at

http://www.hindawi.com
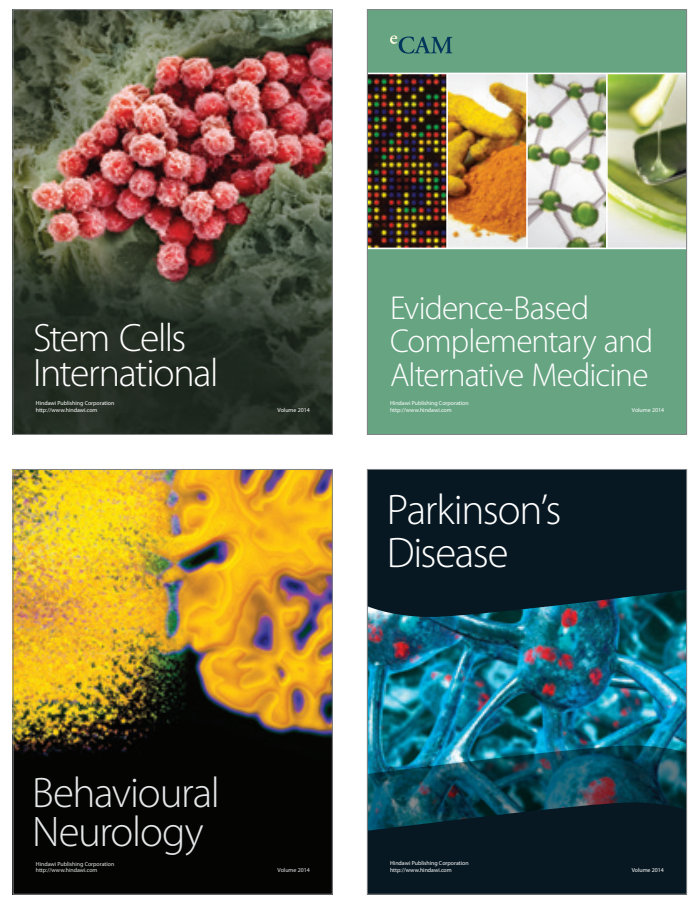
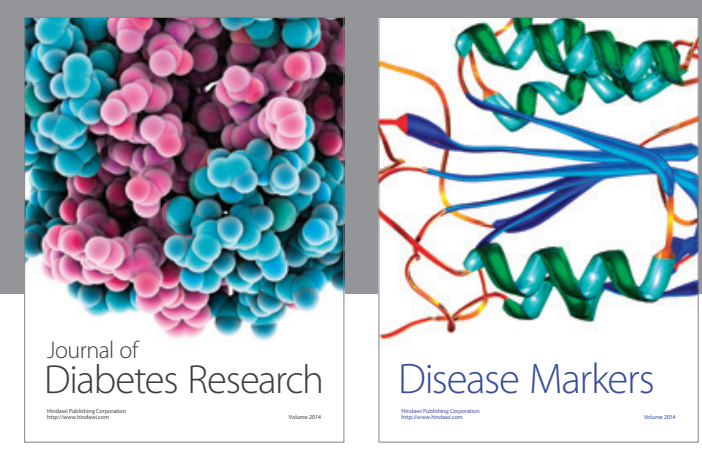

Disease Markers
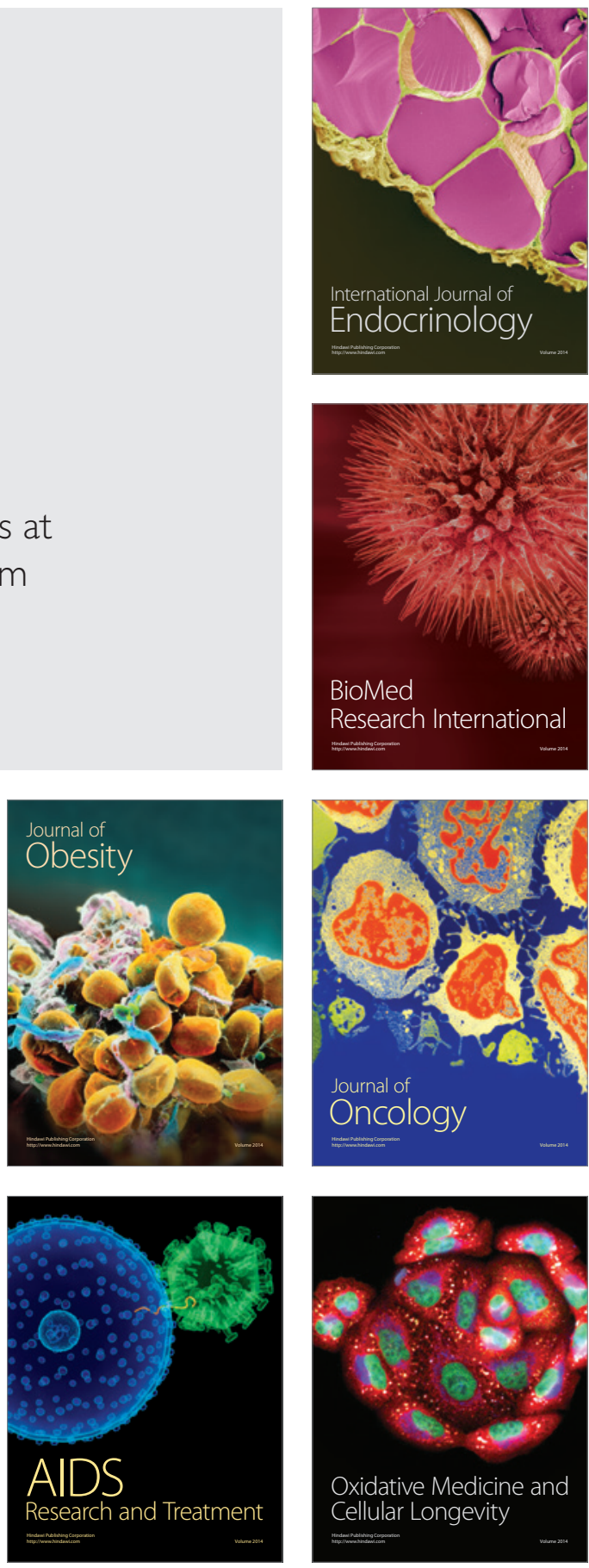